\title{
Research on Mechanical Properties of Different Cement-soils in Zaozhuang
}

\author{
Wenting $Q u^{1, a}$, Hongfei $X u^{1, b}$ \\ ${ }^{1}$ Civil Engineering and Architecture Institute, Zaozhuang University, ZaoZhuang, Shandong, China \\ aquwenting216@126.com, buhongfei2012@163.com
}

Keywords: cement-soil;cement content;age;unconfined compressive strength

Abstract. Mechanical properties of different cement-soil in Zaozhuang are studied in this paper. Clay and silt are two kinds of foundation soil widely distributed in Zaozhuang University which are choosed to make cemented soil samples.The influence of cement content and curing age on unconfined compressive strength of these two different cement-soil samples are respectively studied.The test results show that the unconfined compressive strength of cement-soil increases with the increase of cement content.Through comparing the results of different cement-soil,the optimum cement content is choosed which is $20 \%$ for cemented clay and $15 \%$ for cemented silt. The influence of curing age on unconfined compressive strength of cement-soil is that the strength increases with the extension of age and the growth rate is large before $28 \mathrm{~d}$ while it is much smalller after $28 \mathrm{~d}$. On the whole, the unconfined compressive strength of cemented clay is higher than that of cemented silt.

\section{Introduction}

The mechanism of cement-soil is that the cementation of cement hardens the mixture and then a solidified body is formed ${ }^{[1]}$. Cement-soil is mainly used for improving the strength and modulus of soil in engineering and its mechanical properties are influenced by many factors.

The strength of cement-soil is greatly influenced by cement content.In a certain range of cement content,the compressive strength of cement-soil increases significantly with the increase of dosage.But the increasing extent of compressive strength is limited outside this range. Reasonable cement content should be 5\%-30\% generally ${ }^{[2]}$.Study results show that the shear strength of cement-soil increases with the increase of cement content and age ${ }^{[3]}$.A concept of quasi-water-cement ratio is proposed for predicting unconfined compressive strength of cemented clays by Chu $\mathrm{Chengfu}^{[4]}$.A lot of studies about the influence of ages on strength have been conducted.Cement-soil strength increases rapidly before $28 \mathrm{~d}$ age. The strength still has a large increase from $28 \mathrm{~d}$ to $90 \mathrm{~d}$ age, but the pace of increase is significantly slower ${ }^{[5]}$. Soil water content also has a great influence on the strength of cement-soil.Generally speaking,when water content of soil decreases $10 \%$, compressive strength of cement-soil increases $10 \% \sim 50 \%{ }^{[6]}$. But the experimental studies show that too low water content will influence the agitation effection of cement-soil,thus influencing cement-soil strength ${ }^{[7]}$.

This study is based on the fact of Zaozhuang area.The influence of cement content and curing age on unconfined compressive strength of different cement-soil samples are respectively studied through laboratory tests.

\section{Test scheme}

Test materials.Clay and silt in Zaozhuang University are used to make cemented soil.The cement is ordinary Portland cement P.O32.5.The natural and air-dry moisture content of clay and silt are shown in Table.1. 
Table.1 natural and air-dry moisture content of soils

\begin{tabular}{ccccc}
\hline soils & natural clay & air-dry clay & natural silt & air-dry silt \\
\hline moisture content $(\%)$ & 16.23 & 4.6 & 11.67 & 5.4
\end{tabular}

Test scheme.This paper researches the influences of cement content and curing age on mechanical properties of different cemented soils,choosing unconfined compressive strength as a main mechanical index. The test scheme is shown as follows.

The water-cement ratio is 0.8 . The sample size is cube with the side length of $70.7 \mathrm{~mm}$.Four cement contents choosed are 10\%,15\%,20\% and 25\% .Cement-soil samples made of different soils and using different cement contents are cured for $7 \mathrm{~d}, 28 \mathrm{~d}$ and $45 \mathrm{~d}$ respectively and strength at different ages are measured. The mix ratio of cement-soil is shown in Table. 2 .

Table. 2 Mix ratio of cement-soil

\begin{tabular}{ccccc}
\hline \multirow{2}{*}{ soils } & cement content $(\%)$ & air-dry soils $(\mathrm{g})$ & cement $(\mathrm{g})$ & water $(\mathrm{ml})$ \\
\hline \multirow{4}{*}{ clay } & 10 & 6000 & 667 & 1200 \\
\cline { 2 - 5 } & 15 & 6000 & 1000 & 1466 \\
\cline { 2 - 5 } & 20 & 6000 & 1333 & 1732 \\
\hline \multirow{4}{*}{ silt } & 25 & 6000 & 1667 & 2000 \\
\cline { 2 - 5 } & 10 & 6000 & 636 & 865 \\
\cline { 2 - 5 } & 15 & 6000 & 953 & 1118 \\
\cline { 2 - 5 } & 20 & 6000 & 1271 & 1373 \\
\hline
\end{tabular}

\section{Analysis of test results}

Influence of soil type on strength of cement-soil.Compressive strength of different cemented soils are measured.Test results are shown in Table.3.

Table 3 Compressive strength of different cemented soils

\begin{tabular}{ccccccccc}
\hline & \multicolumn{3}{c}{ strength of cemented clay(MPa) } & \multicolumn{3}{c}{ strength of cemented silt(MPa) } \\
\hline age(d)content & $10 \%$ & $15 \%$ & $20 \%$ & $25 \%$ & $10 \%$ & $15 \%$ & $20 \%$ & $25 \%$ \\
\hline 7 & 2.1 & 2.5 & 3.3 & 3 & 1.4 & 2 & 1.9 & 2.6 \\
\hline 28 & 7 & 7.8 & 8.3 & 9.6 & 5 & 6.5 & 6 & 7.3 \\
\hline 45 & 7.3 & 7.4 & 8.2 & 10.4 & 5.3 & 6.9 & 6.7 & 8 \\
\hline
\end{tabular}

When cement content and the age are same,strength of cemented clay are higher than that of cemented silt.The reason may be that the physical and chemical reactions among clay,cement and water are sufficient due to fine particles,high plasticity and high cohesiveness of clay so that the strength are higher. However, low water content,low plasticity and poor water retention of silt cause low strength.

Influence of curing age on strength of cement-soil. The variation trend of cement-soil compressive strength with curing age is shown in Figure.1. 

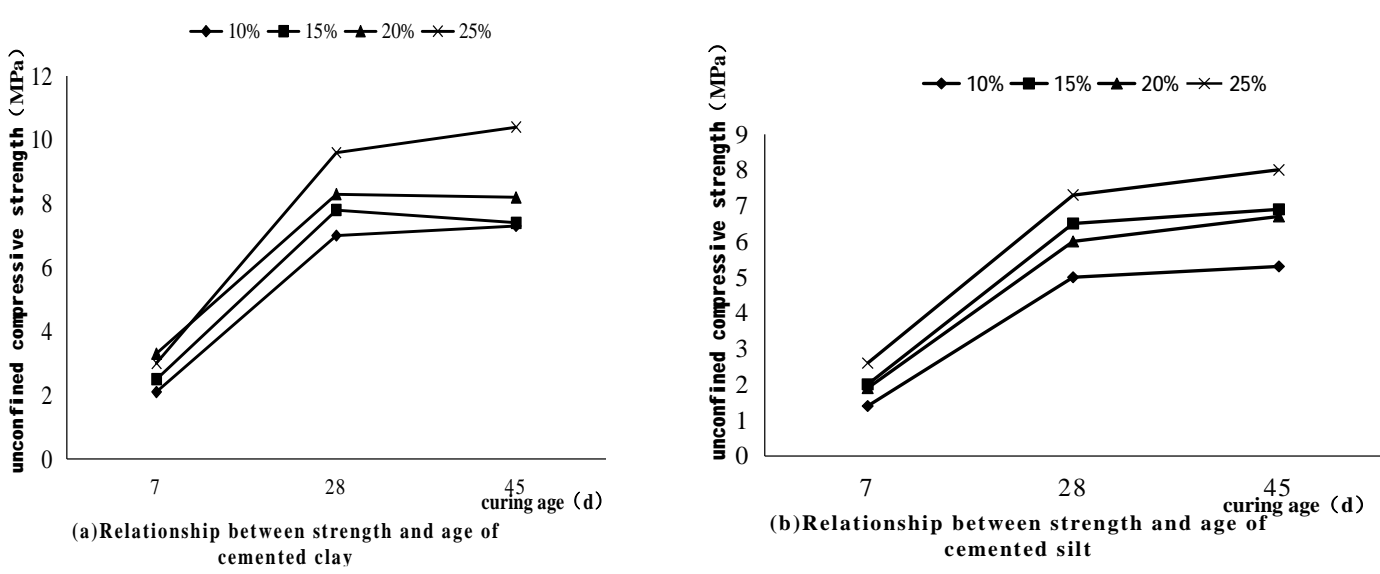

Figure.1 Relationship between strength and age of cement-soil

The following conclusions can be drawed through analysis of the trend of line charts.

(1)Compressive strength of cemented soils increase with the increase of curing age.

(2)The growth of compressive strength of cemented soils is fast before $28 \mathrm{~d}$ and it is slow after $28 \mathrm{~d}$. The compressive strength at $28 \mathrm{~d}$ is more than $90 \%$ of compressive strength at $45 \mathrm{~d}$.

(3)There is still an increasing trend of strength at $45 \mathrm{~d}$.Compared with concrete material,the growth of stength of cemented soils with age is slower.So it is necessary to further extend the curing age and research strength growth trend,thus determining reasonable curing age for cement-soil.

The influence of cement content on strength of cement-clay. The relationship between unconfined compressive strength and cement content of cement-clay is shown in Figure.2.

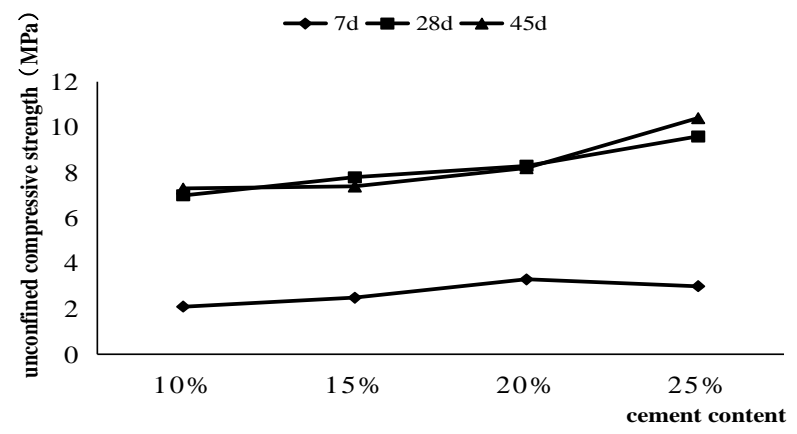

Figure. 2 The relationship between strength of cemented clay and cement content

The following conclusions can be seen from Figure. 2 .

(1)The overall trend is that the compressive strength of cement-clay increases with the increase of cement content.

(2)For cemented clay,the increase of compressive strength is not significant when the cement content change from $20 \%$ to $25 \%$. And in early stage of curing ( $7 \mathrm{~d}$ age) , the compressive strength decreased slightly when cement content increased from $20 \%$ to $25 \%$.

(3)Considering mechanical properties only,the cement content used in consolidation of clay foundation in Zaozhuang area should be $25 \%$.However, considering both the effect of reinforcement and economic factors, the optimum cement content is $20 \%$.

The influence of cement content on strength of cement-silt. The relationship between unconfined compressive strength and cement content of cement-silt is shown in Figure.3. 


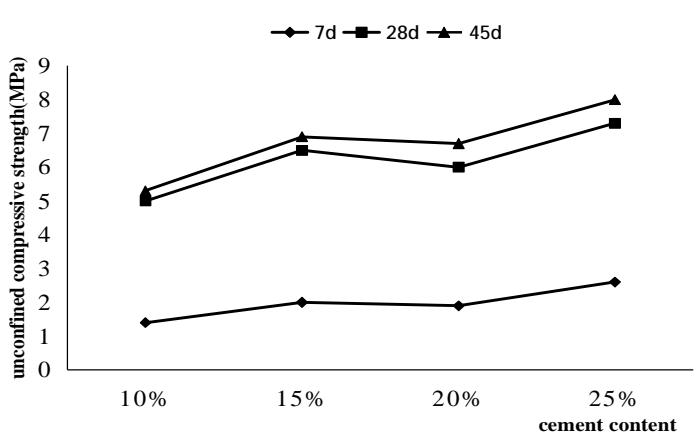

Figure. 3 The relationship between strength of cemented silt and cement content

The following conclusions can be seen from Figure 3 .

(1)The overall trend is that the compressive strength of cement-silt increases with the increase of cement content.But the compressive strength decreased slightly when cement content increased from $15 \%$ to $20 \%$.

(2)Considering both the effect of reinforcement and economic factors, the optimum cement content is $15 \%$. However, when the strength requirement is high, the amount of cement should be $25 \%$.

\section{Conclusions and prospects}

This study is based on the fact of Zaozhuang area.The influence of cement content and curing age on unconfined compressive strength of different cement-soil samples are respectively studied through laboratory tests. The main conclusions are as follows.

(1)The mechanical properties of cement soil are affected by soil type.As far as the two kinds of soils chosen in this paper,unconfined compressive strength of cemented clay are higher than that of cemented silt.So the reinforcement effect of cement-clay is better.

(2)Compressive strength of cemented soils increase with the increase of curing age. The growth of compressive strength of cemented soils is fast before $28 \mathrm{~d}$ and it is slow after $28 \mathrm{~d}$. The compressive strength at $28 \mathrm{~d}$ is more than $90 \%$ of compressive strength at $45 \mathrm{~d}$.

(3)For cemented clay,the unconfined compressive strength increases with the increase of cement content.But the increase of compressive strength is not significant when the cement content change from $20 \%$ to $25 \%$. And in early stage of curing ( $7 \mathrm{~d}$ age), the compressive strength decreased slightly when cement content increased from $20 \%$ to $25 \%$.Considering mechanical properties only,the cement content used in consolidation of clay foundation in Zaozhuang area should be $25 \%$.However, considering both the effect of reinforcement and economic factors, the optimum cement content is $20 \%$.

(4)For cemented silt,the unconfined compressive strength increases with the increase of cement content.But the compressive strength decreased slightly when cement content increased from $15 \%$ to $20 \%$.Considering both the effect of reinforcement and economic factors, the optimum cement content is $15 \%$. However, when the strength requirement is high, the amount of cement should be $25 \%$.

In this paper,only two kinds of soils in Zaozhuang are studied and only the age and cement content are considered as influence factors.Further researches are needed in many ways.In subsequent studies,other soils in Zaozhuang area can be researched. It is necessary to extend the curing age and research strength growth trend,thus determining reasonable curing age for cement-soil.

\section{References}

[1]Zhang Dengliang.Principle of reinforced soil[M].Beijing:China Communications Press, 1990:81-93. 
[2]Gao Songhe.Experimental study on mechanical properties of different cement-soils. Construction Technology,2014,(43):84-89.

[3]Zhang Jiazhu,Cheng Zhao,Yu Jinhuang.Experimental study on properties of cement-soil[J]. Geotechnical Engineering Technique,1999,(3):38-40.

[4]Chu Chengfu,Hong Zhenshun,Liu Songyu.Prediction of unconfined compressive strength of cemented soils with quasi-water-cement ratio.Rock and Soil Mechanics,2005,26(4):645-650.

[5]Chen Da,Zhuang Ning,Liao Yingdi,Huang Hui.Experimental study on development law of mechanical properties of cement soil with age.Jiangsu:Hydro-Science and Engineering, 2012,

(1):26-29.

[6]Gong Bining,Li Songquan.Study on physical and mechanical characteristics of deep jet mixing strengthening soil for soft foundations.Journal of Hohai University(Natural Sciences), 2000, 28 (2):101-105.

[7]Lin Peng,Xu Shuxian,Xu Zhenhong.Indoor experiment on strength of cement-treated soft clay.West-China Exploration Engineering,2002,14(4):24-26. 